\title{
Ismar de Oliveira Soares: a memória dos estudos comunicativos-educativos e da educomunicação no Brasil
}

\section{Adilson Citelli}

Professor titular no Departamento de Comunicações e Artes e do Programa de Pós-Graduação em Ciências da Comunicação da ECA-USP. É coordenador do Grupo de Pesquisa MECOM e bolsista $1 B$ do CNPq. Editor da revista Comunicaşão E゚ Educação.

E-mail: citelli@uol.com.br

\section{Cláudia Nonato}

Professora convidada do CELACC (ECA/USP), vice coordenadora do Centro de Pesquisa em Comunicação e Trabalho (CPCT-ECA/USP) e Editora Executiva da revista Comunicação $\mathcal{E}$ Educação.

E-mail: claudia.nonato@uol.com.br

\section{Roseli Figaro}

Livre-docente, coordenadora do Programa de Pós-Graduação em Ciências da Comunicação da USP. Bolsista Produtividade em Pesquisa do CNPq, Nivel 2. Coordenadora do CPCT-ECA/ USP e editora da revista Comunicação Ẽ Educação.

E-mail: figaro@uol.com.br

Resumo: Ismar de Oliveira Soares concedeu remotamente uma entrevista exclusiva à Revista Comunicação \& Educação. A proposta é homenagear o professor Titular Sênior da Universidade de São Paulo, que generosamente nos apresentou os aspectos mais importantes da sua trajetória, diretamente relacionada aos estudos da Comunicação e Educação e, posteriormente, ao conceito de Educomunicação. Nesta entrevista, Soares faz uma recuperação histórica da epistemologia educomunicativa e da sua implantação na ECA/USP; também responde a questões relacionadas ao pensamento
Abstract: This work seeks to honor Ismar de Oliveira Soares, the Senior Professor of the University of São Paulo, who granted an exclusive remote interview to Comunicação \& Educação journal, where he generously presented us with the most important aspects of his career - directly related to communication and education studies and, later, the concept of Educommunication. In this interview, Soares discusses the history of the educommunicative epistemology and its implementation in the School of Communication and Arts (ECA/ USP). The author also answered questions 
de Paulo Freire e à presença das tecnologias no ambiente escolar, além de demonstrar preocupação com a disseminação das fake News e da da EAD nos últimos anos.

Palavras-chave: Ismar de Oliveira Soares; entrevista; comunicação e educação; educomunicação; estudos comunicativos-educativos. related to the thought of Paulo Freire and the presence of technologies in the school environment, besides demonstrating concern regarding the spread of fake news and the distance education modality in recent years.

Keywords: Ismar de Oliveira Soares; interview; communication and education; educommunication; communicativeeducational studies.

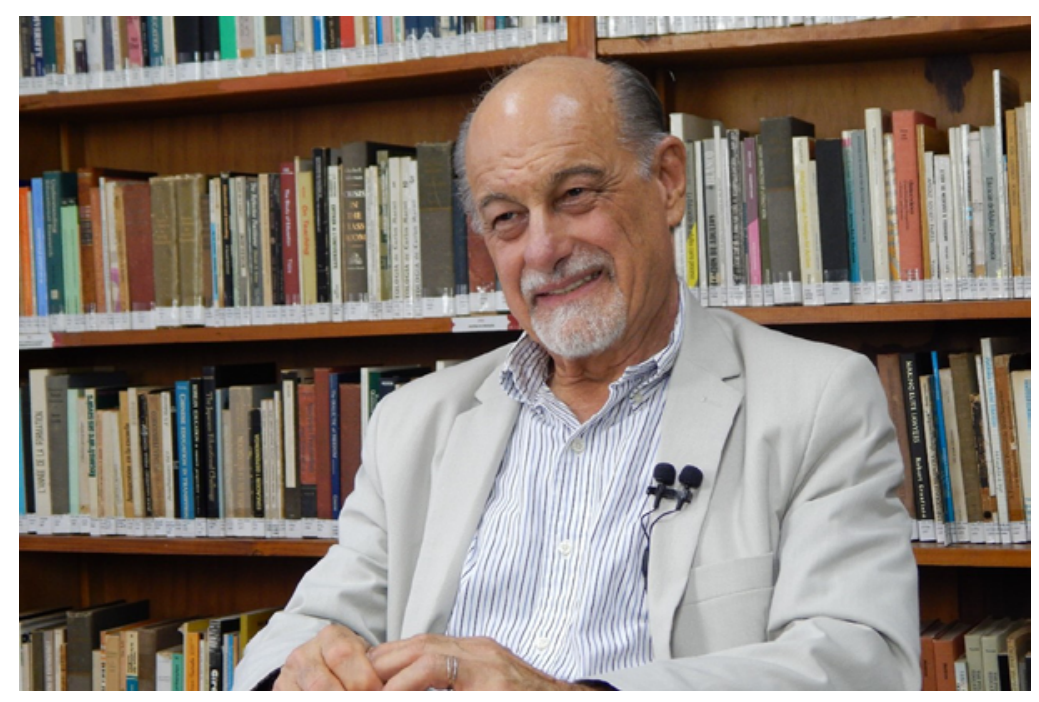

\section{INTRODUÇÃO}

Aos 78 anos de idade, o professor Ismar de Oliveira Soares é Titular Sênior da Universidade de São Paulo. Bacharel em Geografia e Licenciado em História pela Faculdade Salesiana de Filosofia, Ciências e Letras de Lorena, SP (1965). É também jornalista formado pela Faculdade Cásper Líbero (1970), Mestre (1980) e Doutor em Ciências da Comunicação (1986) pela Universidade de São Paulo, com pós-doutorado, concluído em 2000, pela Marquette University Milwaukee, WI, USA. Soares foi coordenador do NCE - Núcleo de Comunicação e Educação da ECA-USP por 18 anos e ressemantizou, em 1999, o neologismo Educomunicação para designar um campo emergente de intervenção social na interface comunicação/educação. Entre seus feitos, promoveu os projetos Educom.TV e Educom. rádio, nos anos 2000; supervisionou a aplicação do Curso Mídias na Educação, do MEC, junto à rede de educação do estado de São Paulo (2008-2012), e coordenou a implementação da Licenciatura em Educomunicação junto à Escola de Comunicações e Artes da USP (2011), tendo exercido a coordenação do curso até sua aposentadoria. Atualmente na presidência da ABPEducom - Associação Brasileira de Pesquisadores e Profissionais da Educomunicação - está à frente da realização dos Encontros Brasileiros de Educomunicação. Ismar Soares também é autor de dezenas de artigos e livros, entre eles "Educomunicação: o conceito, o 
profissional, a aplicação" (2011), que se tornou uma referência para a área. Nesta entrevista para a revista Comunicação $\mathcal{E}^{\mathcal{O}}$ Educação, o professor traz uma preciosa análise do seu percurso acadêmico, a partir da recuperação histórica dos estudos comunicativo-educativos, até a criação do termo Educomunicação e a implantação da licenciatura na ECA/USP, entre outros temas. Atento ao seu tempo, Soares demonstra preocupação com a disseminação das fake news e com a popularização dos cursos de ensino à distância como consequência da pandemia de Covid-19.

\section{Comunicação \& Educação: O que destaca do seu percurso acadêmico e como se voltou para as questões comunicativo-educativas?}

Ismar de Oliveira Soares: Estou envolvido com a comunicação/educação desse o início dos anos 1970, mas foi na década de 1980 que passei a integrar coletivos voltados para o tema, como foi o caso do Projeto de Leitura Crítica da Comunicação LCC, identificado por Raquel Paiva, da UFRJ, como uma iniciativa pioneira na formação de lideranças populares para a análise sistemática das mensagens dos meios de comunicação. O projeto LCC levou-me, por outro lado, a entrar em contato com projetos semelhantes, desenvolvidos em vários países da América Latina, ampliando meu diálogo com pesquisadores como Mario Kaplún, do Uruguay; Valerio Fuenzalida, do Chile; Teresa Quiroz, do Peru e Pablo Ramos, de Cuba.

Ainda nos anos 1980, colaborei com as Edições Paulinas para a fundação e consolidação do Sepac-EP - Serviço à Pastoral da Comunicação das Edições Paulinas. Na área da pesquisa, passei a transitar por duas pistas: uma que me levou às reflexões/atuações no campo da Comunicação Religiosa, área de meu mestrado e doutorado, e outra que me facilitou o acesso ao estudo das relações entre a Comunicação e a Educação, tema da pesquisa que realizei no final da década de 1990, sistematizando o conceito da Educomunicação sob a perspectiva da América Latina.

O resultado da pesquisa foi publicado na revista Contato, do Senado Federal, em 1999, e na revista Comunicação Ẽ Educação, em 2000 e 2002, acabando por dar sustentação a uma série de projetos de intervenções socioeducativas, promovidos por municípios (como o de São Paulo: Educom.rádio), estados (como o de Mato Grosso: Educomrádio.Centro-oeste) e pelo MEC (projeto Mídias na Educação, do MEC) e MMA (Programa de Educomunicação Socioambiental), com o envolvimento de milhares de pesquisadores e agentes culturais que atribuíam a si mesmos o perfil de profissionais da educomunicação.

As pesquisas subsequentes acabaram fornecendo elementos de sustentação para a elaboração da proposta de criação de uma Licenciatura em Educomuicação no espaço do Departamento de Comunicações e Artes da ECA/USP, instalada em 2011. No ano subsequente, nascia a ABPEducom - Associação Brasileira de Pesquisadores e Profissionais da Educomunicação, que, em 2016, apoiou a Unesco na realização, no espaço do ECA/USP, da sua semana internacional 
sobre educação midiática (o Global MIL Week). Em novembro deste mesmo ano, a ABPEducom levava o tema da educomunicação para o Senado, em seminário que contou com a participação de adolescentes de escola pública (EMEF Casa Blanda) e de uma escola privada (Colégio Dante Alighieri), integrantes de uma experiência de prática interinstitucional da educomunicação na cidade de São Paulo: o Projeto Educom.geração-cidadã.

Entre as teses que orientei destaco duas pesquisas: uma, defendida em 2013, que identificou que o projeto Mais Educação, do governo federal, havia facilitado o contato de mais de dois milhões de estudantes de escolas públicas com a prática educomunicativa, entre 2008 e 2012. Já uma segunda, mais atual (2018), que fazia um estudo comparado entre as políticas de educação midiáticas em vigor nos municípios do Rio de Janeiro (que adota o conceito da Mídia-Educação) e de São Paulo (que trabalha, desde 2001, com a Educomunicação).

Tenho testemunhado um avanço do debate sobre o novo conceito no espaço ibero-americano, possibilitado especialmente pelos congressos de Alfamed, Rede Interuniversitária Euroamericana de Investigação sobre Competência Midiática para a Cidadania, com sede em Huelva, Espanha.

\section{C\&E: A preocupação com os vínculos comunicação e educação teve presença no Brasil desde as décadas de 1920-1930. Entre os pioneiros de tal inflexão encontram-se nomes como Roquette Pinto e Anísio Teixeira. Fale um pouco do contributo desses autores para a implantação dos estudos comunicativo-educativos.}

IOS: O primeiro nome escolhido como patrono de um dos 17 polos de formação do projeto Educom.rádio na cidade de São Paulo, ocorrido entre 2001 e 2004, foi o de Roquete Pinto. Fosse ele vivo, teria sido convidado para a inauguração da proposta formativa que implantou a linguagem radiofônica como forma de agregar professores e alunos no combate à violência nas escolas.

Edgard Roquette-Pinto (1884-1954) foi o fundador da radiodifusão brasileira. Como antropólogo, entendia, nos idos de 1920, que não haveria outro modo da educação chegar a todos os cantos do país não fosse pelo uso deste maravilhoso recurso tecnológico. Assim, ao implantar a primeira emissora no Brasil, a Rádio Sociedade do Rio de Janeiro, decidiu que seria essencialmente educativa. Uma rádio com programação infantil, além de aulas formais sobre temas curriculares. Atenção especial dava às cartas dos ouvintes. Em 1936, Roquette doa a emissora ao então Ministério da Saúde e Educação. Na sequência, dedica-se à produção audiovisual, realizando cerca de trezentos filmes de curta-metragem para o Instituto Nacional de Cinema Educativo. Um de seus temas favoritos foi o da miscigenação racial da população brasileira, com uma forte crítica ao determinismo racial e biológico. Uma referência da qual os cursistas do Educom.rádio certamente não se esquecerão. 
Outro patrono das turmas do Educom.rádio foi Anísio Teixeira (1900-1971). Anísio acreditava no poder de transformação social por meio da educação. Defendia a criação de uma rede de ensino que fosse da educação infantil à universidade, e atendesse a todos, independentemente de raça, condição financeira ou credo, e olhasse para os interesses da comunidade em que estava inserida. Foi o que defendeu ao assinar, em 1932, o Manifesto dos Pioneiros da Educação Nova. Sua postura firme influenciou uma nova geração de educadores, como Darcy Ribeiro e Florestan Fernandes.

De maior interesse para a educomunicação foi a criação, em 1961, da Escola Parque, em Salvador, Bahia. Nela, as crianças tinham acesso a uma educação integral. Paralelamente ao ensino dos conteúdos curriculares, os pequenos se envolviam com as linguagens artísticas, como o teatro, o cinema e a música. Foi a forma que encontrou para preparar a nova geração para a cidadania e para o mundo do trabalho. Não é por acaso que a educomunicação, nos dias de hoje, encontra na escola pública seu mais ativo espaço de expressão.

\section{C\&E: Nos anos 1960 houve incremento importante nas} preocupações latino-americanas com os problemas suscitados pela interface comunicação-educação. Há um cenário histórico que contribuiu para a emersão de tal interesse?

IOS: Duas bandeiras foram levantadas e ganharam adeptos, a partir da segunda metade do século XX: as tecnologias educativas e a leitura crítica da comunicação. A primeira girava em torno da didática: como melhorar a transmissão de conteúdos utilizando recursos como os "dispositivos" e os filmes educativos. Teve continuidade nos programas voltados para as TIC na Educação, de caráter tecnicista.

A segunda preocupava-se com o viés ideológico da produção midiática: como defender o usuário do controle da mídia hegemônica e de suas possíveis manipulações. Esta bandeira sofreu mutações nas décadas subsequentes, devido especialmente à aplicação dos postulados dos Estudos Culturais, que discutiam o papel dos consumidores das mensagens midiáticas, condenando a "teoria do impacto" e valorizando as mediações culturais presentes nos processos de comunicação.

No embate entre estas correntes, ganharam espaço as reflexões de teóricos como o boliviano Luis Ramiro Beltrán, o brasileiro Paulo Freire, o uruguaio Mario Kaplún, todos com uma média de idade entre 30 e 40 anos, entre as décadas de 1960 e 1970.

Beltrán apontou para a especificidade de uma emergente teoria latino-americana de comunicação, em oposição ao modelo funcionalista vigente, com reflexos nos modos de se pensar e desenvolver práticas educativas. Freire, sinalizando para o caráter necessariamente dialógico da ação educativa, e Kaplún, conhecido como um excelente leitor de Freire, implementando programas de recepção ativa junto a lideranças comunitárias de diferentes países do continente, 
a partir do uso dos próprios recursos midiáticos acessíveis. A estes pensadores somaram-se Jesús Martín-Barbero, na Colômbia; Francisco Gutierrez, na Costa Rica; Valerio Fuenzalida, no Chile, Prieto Castilho, na Argentina e Guillermo Orozco Gómez, no México, entre muitos outros.

É nesse contexto, que o tema da inter-relação Comunicação/Educação avançou, convertendo-se em objeto específico de estudo, traduzido, por exemplo, na criação de uma revista como Comunicação \& Educação, no Brasil, nos inícios dos anos de 1990.

\section{C\&E: O termo educomunicação ganhou proeminência nos anos 1980-1990. Explicite os motivos que promovem tal escolha vocabular. Trata-se de viragem epistemológica, perspectiva para enfrentar os desafios colocados na interface comunicativo-educativa, ou uma maneira de promover os vínculos entre a pesquisa acadêmica e os projetos de intervenção social? Ou seria tudo isso junto, entre outros fatores?}

IOS: Não há dúvida: tudo isso junto! Na verdade, o termo Educommunication, em inglês, já vinha sendo usado ocasionalmente pela Unesco, antes da entidade oficializar sua preferência pela expressão Media Education, nos inícios dos anos de 1980.

Ao longo das últimas seis décadas o termo "Educomunicação" continuou a ser usado, na maioria dos casos, para designar uma aproximação genérica e abrangente entre o ensino e as tecnologias da informação. O sentido hoje atribuído pela comunidade latino-americana, no sentido de designar um "campo de interface", com epistemologia própria, áreas de intervenção socioeducativa específicas e metodologias de ação definidas, resultou de uma sistematização possibilitada, no final dos anos de 1990, por um conjunto de pesquisas no continente, entre as quais o trabalho desenvolvido pelo NCE/USP, entre 1997-1999, com o apoio da Fapesp.

No caso, reconhecia-se a consolidação de um pensamento e de uma prática que havia emergido das lutas sociais do continente latino-americano, e que - indo além da "educação para a mídia" - assumia como fundamental a formação para uma gestão compartilhada e democrática da comunicação nos espaços educativos, mediante a valorização do direito universal à expressão, privilegiando a cidadania em relação ao mercado.

A consolidação do conceito pode ser constatada no conjunto das 416 teses e dissertações, defendidas em mais de cem centros de pós-graduação pelo país, segundo documenta o banco de teses da Capes, em junho de 2021. 


\section{C\&E: Nos anos 2011 foi criada a Licenciatura em Educomunicação na ECA-USP. Poderia, como um dos ativos participantes da iniciativa, explicitar as razões que moveram a implantação desse pioneiro programa no Brasil?}

IOS: A Licenciatura em Educomunicação surgiu num cenário marcado pelo entrelaçamento de diferentes ocorrências envolvendo docentes e pesquisadores do Departamento de Comunicações e Artes, como: (1) A possibilidade que se abriu para o departamento no sentido de criar novos programas de formação, em meados dos anos 1990, em decorrência da extinção do ciclo básico comum a todos os cursos da Escola, até então sob sua responsabilidade; (2) a excelência do corpo docente, com diferentes formações e disposto a fazer frente, sob a liderança da Profa. Maria Aparecida Bacela, ao processo de fragmentação dos programas de graduação até então oferecidos pela ECA/USP; (3) a opção inicial de um grupo de professores em desenvolver um curso de especialização em "Gestão de Processos Comunicacionais”, superando a fragmentação da formação na área. A certificação de 680 especialistas em 17 edições do curso, ofereceu ao corpo docente do CCA um aprendizado sobre como oferecer formação transdisciplinar na área da comunicação, aproximando a gestão comunicativa a uma proposta dialógica de educação; (4) a criação da Revista Comunicação \& Educação, em 1994, como uma atividade vinculada ao programa de especialização; (5) a repercussão de texto publicado na revista Contato, editada na época pelo gabinete do Senador Artur da Távola, sobre os resultados da pesquisa do NCE/USP sobre a emergência do campo da educomunicação (1997-1999); e (6) o convite da Secretaria de Educação da Prefeitura de São Paulo para o desenvolvimento de uma programa educomunicativo que levasse à redução da violência nas escolas do municipais. $\mathrm{O}$ projeto, que contou com a participação de um número significativo de docentes e estudantes da ECA/USP, teve a duração de quatro anos (2001 a 2004), formando onze mil pessoas, entre professores e estudantes de 455 escolas, convertendo-se na primeira política de educomunicação do país. Já estava pavimentado o caminho para uma decisão mais ousada: criar um curso de graduação, em nível de licenciatura, com o reconhecimento, pela Universidade, de que um novo campo de agir profissional havia se estabelecido na interface comunicação/educação, necessitando de formação superior competente. Por outros caminhos e outras circunstâncias, a Universidade Federal de Campina Grande fazia, simultaneamente, a sua opção pela habilitação em Educomunicação, em nível de bacharelado.

\section{C\&E: Neste ano de 2021 é comemorado os 100 anos de Paulo Freire. Existe influência do pensamento freireano na configuração da perspectiva educomunicacional?}

IOS: Quando o Educom.rádio foi implantado, a partir de 2001, não poucos professores da rede municipal de São Paulo alertavam: "Mas, isso é Paulo Freire!". Referiam-se à meta do programa em fazer uso de procedimentos dialógicos e 
colaborativos de comunicação para enfrentar o problema que afligia a todos: a violência nas escolas. Alguns se lembravam que Freire havia usado o rádio para desenvolver o MEB - Movimento de Educação de Base, nos anos de 1960. Outros, ainda que - enquanto Secretário de Educação da prefeitura - o educador, ao instalar a informática educativa, costumava alertar para o perigo do Cavalo de Tróia: o que poderia vir embutido com o ingresso das novas tecnologias no espaço escolar! Na verdade, Paulo Freire, ao lado de Mário Kaplún, é referência universalmente aceita quando se busca identificar os ideólogos que questionavam a verticalidade da prática educativa tradicional e a instrumentalização da didática pelas TIC. Os dois ofereceram subsídios que possibilitaram aos educomunicadores entender o papel a ser cumprido pela educação na ressignificação das relações entre os humanos, a indústria de artefatos digitais e as corporações que as dominam. Na verdade, Kaplún aplicou Freire especialmente na formatação de práticas comunicativas no espaço não formal da educação popular. E os atuais especialistas, muitos deles implementando políticas públicas na área, passaram a ser devedores de ambos.

\section{C\&E: Sob qual ângulo a educomunicação considera a presença das novas tecnologias da informação e da comunicação nos ambientes escolares?}

IOS: Não há sombras de dúvidas de que as mediações tecnológicas sempre rondaram as relações entre mestres e discípulos, da idade dos papiros aos tempos da cibercultura. No caso, a pergunta da educomunicação não é sobre o que o recurso tecnológico pode fazer para a educação, mas o que a educação deve fazer com as técnicas disponibilizadas, a cada novo período da história.

Em resposta à presente pergunta, diria que três ângulos necessitam ser contemplados, um de natureza cognitiva, outro, de natureza operativa e um terceiro, de natureza política. Trata-se de ênfases, frente a uma única e grande proposta educativa: desenvolver um relacionamento adequado entre a área da educação, de um lado, e a área que protagoniza os processos de comunicação mediados pelas tecnologias da informação, de outro. Primeiro, faz-se necessário conhecer este universo, na medida justa para cada faixa etária e no contexto de cada fase do processo de aprendizagem. Em decorrência, ou mesmo como metodologia de abordagem pedagógica, é importante a introdução das crianças e jovens a um crescente empoderamento, que lhes permita o domínio sobre os possíveis usos dos recursos disponibilizados. Finalmente, a pergunta pelo "para quê". É o ângulo político, que irá permitir ao estudante identificar seu papel: enquanto um consumidor assumido, dentro das regras do mercado, ou um cidadão consciente de seus direitos e deveres no campo, disposto a assumir posturas ativas, para a correção de rumos, na espera de suas possibilidades. Referimo-nos, aqui, ao papel da educomunicação como espaço para o exercício ativo e democrático dos recursos da comunicação no próprio ambiente escolar, 
unindo o conhecimento e a operação dos equipamentos disponibilizados a uma perspectiva de prática cidadã em favor dos grandes interesses coletivos.

Na verdade, a Educomunicação diz respeito à cidadania, às relações democráticas e ao manejo compartilhado da gestão dos processos tecnológicos. Este é o momento em que, a partir da prática, o estudante entenderá a diferença entre um modelo funcionalista de comunicação, próprio da Indústria Cultural e um modelo dialético inerente à ação educomunicativa.

\section{C\&E: Assistimos a um crescendo da chamada pós-verdade,} das fake news, das pautas regressivas que impactam em questões como a dos costumes, do negacionismo científico, da tentativa de corroer a democracia. A educomunicação pode trazer contributos para desarmar tal roteiro?

IOS: O termo "pós-verdade" é muito singelo e delicado para identificar a realidade da entronização da mentira como eixo estruturador da política. E o fenômeno foi possível justamente pela perda do controle da sociedade sobre a mais articulada estrutura informacional de que o mundo tenha tido conhecimento, as denominadas "Redes Sociais Robotizadas" que, em mãos de quadrinhas, investem contra toda forma de mediação, incluindo as tradicionalmente exercidas a partir de competências profissionais estruturadas e socialmente reconhecidas, com auto regulação ou sujeitas a normas e vigilância legalmente instituídas, incluindo, entre outros, os cientistas, os jornalistas, os agentes da cultura e os professores. Estamos - nós e nossos dados - nas mãos de megacorporações que não devem obediência a nenhuma potestade ou legislação, por serem supranacionais. A mentira tem metas, produz consequências e mantém-se impune. Num primeiro momento, imaginou-se que programas de checagem de notícias reduziriam a produção e o impacto das falsas verdades. Ledo engano, dado o volume e a agilidade dos grupos envolvidos e, especialmente a rapidez da circulação dos dados no ambiente digital.

Lamentavelmente, a Educomunicação não é capaz de desarmar este roteiro. O que ela permite é a ampliação da consciência coletiva sobre a natureza do problema, favorecendo as novas gerações para que encontrem caminhos para sua autodefesa e a defesa da democracia constantemente ameaçada.

\section{C\&E: Mas, um certo deslumbramento com as redes sociais parece crescer, levando em conta as possibilidades de conexão que oferecem. O que a Educomunicação tem discutido sobre o tema e quais reflexões têm proposto?}

IOS: Na verdade, a revolução tecnológica nos mergulhou, de forma explosiva, a partir do final da década de 1990, na ambiência pela qual havíamos tanto sonhado nas décadas anteriores: o acesso livre aos recursos da comunicação 
que, no imaginário de muitos, poderia quebrar os clássicos binômios opressor/ oprimido ou manipulador/manipulado.

A expectativa era a de que, com a melhoria do aparato técnico, a comunicação de resistência deixasse de ser alternativa, voltada a segmentos restritos da população, passando a representar uma modalidade de ação com irresistível potencial mobilizador, tendo como limite apenas a maior ou menor criatividade dos comunicadores populares, e a coerência e grandeza de seu espírito público.

O sonho libertário foi, contudo, colhido de surpresa: o mercado tecnológico que rege a inovação acabou por determinar - ele próprio e sem prever rotas de fuga - as modalidades de seu uso.

No caso da Internet, estabelecia-se a trilogia das necessidades a serem contempladas: informação/entretenimento/comércio, integrada num ecossistema movido pela exaltação egóica, com indivíduo (influenciadores digitais, youtubers etc.) substituindo o coletivo, contando para tanto com uma estrutura robótica que subverteu totalmente a razoabilidade da comunicação humana. Nesse jogo, a maioria absoluta dos usuários passou a satisfazer-se, agradecidamente, com o papel de replicadores cegos a eles concedido, sentindo-se recompensados por ter audiência para o que viesse a retransmitir.

Desafortunadamente, a Internet e o mundo infanto-juvenil têm tido dificuldades de mútua convivência. Foi o que revelou a pesquisa Kids online, do CETIC. br (2019), depois de constatar o quanto as crianças e jovens brasileiros sentem-se afetados pelo aumento significativo de informações falsas e por comentários discriminatórios na Internet. No caso, $48 \%$ das meninas e 33\% dos meninos pesquisados apontavam que haviam sido molestados na Internet. Um total de $33 \%$ de meninas se referia às questões de raça e cor e outro, de $26 \%$, reclamava de referências desabonadoras à aparência física.

Em termos didático-escolares, ao longo do ano 2020, devido à pandemia, os jovens, além de serem vitimados pela iniquidade representada pela falta de oportunidades de acesso a uma Internet segura para seus deveres escolares, acabaram sendo obrigados a conviver, em $75 \%$ dos casos, com a plataforma digital que mais semeia a desinformação - o WhatsApp -, único recurso de que dispunham professores das redes públicas para dar assistência a seus alunos, como revela pesquisa da Fundação Carlos Chagas.

Uma resistência ou qualquer mudança significativa no contexto analisado está condicionada a uma vontade política de intenso diálogo social, que implica em dispositivos legais de proteção, investimentos em práticas socialmente aceitáveis e, especialmente, formação para o uso e o emprego adequados das novas tecnologias no cotidiano da vida social e, em especial, na prática educativa.

A sociedade reage, com a Unesco estabelecendo o combate à desinformação como prioridade número um de sua política de educação midiática e informacional. A própria mídia profissional coloca-se em campo para os serviços de checagem das Fake News, ensaiando aliar-se com os educadores para promover programas de formação de "receptores críticos".

Está em jogo a formação de ecossistemas cognitivo-afetivo-comunicativos que acolham as pessoas e grupos apaixonadas por uma comunicação humana justa, 
equilibrada e solidária. A imagem que encontramos para representar este esforço é a consolidação do conceito de Buen Vivir, em comunidades vinculadas aos povos da Cordilheira dos Andes, em países como Bolívia, Peru e Equador. Nesses espaços, todo o trabalho, do político ao educativo, passa pela meta comum de libertar a natureza escravizada pelo colonizador. Um cativeiro que subornou tanto a vida econômica, quanto a política e a cultural. A harmonia buscada é essencialmente educomunicativa, pois é construída, fio-a-fio, como uma grande manta nas cores e desenhos que se queira estampar. Para os andinos, a vivência de práticas educomunicativas desde a infância à vida adulta, nas escolas e nas comunidades, permite às novas gerações refletir sobre o significado e as implicações de suas falas coletivas, animando-as a fazer frente a toda manipulação, vestida esta da roupagem que for.

\section{C\&E: Em plena pandemia da Covid-19, cresceu muito a} oferta de cursos à distância, aulas síncronas e remotas e, sobretudo, promessas de formação rápida e eficaz, sem custos elevados, em cursos de EAD. Como a educomunicação vê esse cenário?

IOS: Vê com muita angústia. Se na normalidade da educação presencial já era difícil controlar a qualidade do ensino, imagine-se em processos que eliminam toda possibilidade da mediação do Estado, através dos órgãos avaliadores competentes.

O problema não é tão somente a modalidade à distância de se promover o ensino, mas, antes disso, a absoluta inexistência de recursos tecnológicos, ou a falta de acesso aos existentes, para permitir igualdade de acesso.

A lição que ficou do impacto da pandemia na educação foi a de que o país não se havia preparado, nem técnica nem pedagogicamente, para dispor do mínimo razoável para atender as necessidades corriqueiras dos processos de ensino. No entanto, há que se observar e louvar o mérito de um número significativo de docentes, do ensino básico ao universitário, de campearem seus estudantes, indo ao seu encontro, para que tivessem um mínimo de atenção e de contato.

Quanto às promessas de formação rápida e eficaz sem custos elevados em cursos de EAD, as vemos como um marketing de mal gosto. Tememos pelo que sobrará deste desterro, se a educação continuar a ser pensada não como um direito de todos, mas como um serviço qualquer, a ser prestado para quem por ele possa pagar.

Quanto à educação a distância, em si mesma, observados os seus protocolos e dadas as devidas condições de acesso, poderá representar um recurso auxiliar aos programas de ensino, em balanço com as diferentes formas de abordagem nas relações de aprendizagem. Pela perspectiva da Educomunicação, quanto mais dialógico for o processo de tutoria, e quanto mais interativo for o contato entre os próprios alunos, ainda que na modalidade virtual, mais possibilidades ocorrerão de um efetivo processo de educação como uma construção colaborativa do conhecimento e sua aplicabilidade social. 